\title{
Daily physical activity patterns among aging workers: the Finnish Retirement and Aging Study (FIREA)
}

\author{
Anna Pulakka, ${ }^{1}$ Tuija Leskinen, ${ }^{1}$ Annemarie Koster, ${ }^{2}$ Jaana Pentti, ${ }^{1,3}$ Jussi Vahtera, \\ Sari Stenholm
}

- Additional material is published online only. To view please visit the journal online (http://dx.doi.org/10.1136/ oemed-2018-105266).

${ }^{1}$ Department of Public Health, University of Turku, and Turku University Hospital, Turku,

Finland

${ }^{2}$ Department of Social Medicine, CAPHRI Care and Public Health Research Institute, Maastricht University, Maastricht, The Netherlands

${ }^{3}$ Department of Public Health, Faculty of Medicine, University of Helsinki, Helsinki, Finland

Correspondence to Dr Anna Pulakka, Department of Public Health, University of Turku and Turku University Hospital, Turku Fl-20014, Finland; anna.pulakka@utu.fi

Received 1 June 2018 Revised 24 September 2018 Accepted 1 October 2018 Published Online First 23 October 2018

\begin{abstract}
Objectives Physical activity is associated with the aging workers' ability to work and predicts working beyond retirement age. To better understand physical activity behaviour in this growing population group, we aimed at characterising 24-hour physical activity patterns among aging workers, and to describe the association between occupational category and total, occupational and leisure-time physical activities.
\end{abstract}

Methods We included 878 workers (mean age 62.4 years, SD 1.1, 85\% women) from the Finnish Retirement and Aging Study, who wore an accelerometer on their non-dominant wrist for 1 week. We plotted mean hourly activity counts per minute (CPM) for working days and days off. We also compared mean daily CPM between genders and occupations between working days and days off, and work and leisure time by using repeated measures analysis of variance.

Results Activity patterns were different between genders, occupations and types of the day. Women (2580, 95\% Cl 2540 to 2620 ) had higher daily mean CPM than men $(2110,95 \% \mathrm{Cl} 2020$ to 2000). Women in manual occupations were more active than women in non-manual occupations during working days. The differences among men were in the same direction but less pronounced than among women. We found no differences in activity levels between occupations during days off and leisure time on working days.

Conclusions In aging workers, physical activity differs by gender and occupation during working time, but not during leisure time. As low physical activity is associated with increased risk of early exit from employment, physical activity should be promoted at workplaces, especially among men and people in non-manual occupations.

\section{INTRODUCTION}

Physical activity can occur in different domains: transportation, occupation and leisure-time. Generally, non-manual occupational status has been found to associate with more total or leisure time physical activity, but with less occupational physical activity. ${ }^{2}$ However, the research on physical activity across different occupations has mostly relied on self-reported measures of physical activity, ${ }^{1}$ which usually capture only moderate-to-vigorous physical activity (MVPA) and are prone to reporting bias. ${ }^{3}$ Studies using objective physical activity measures have found that employees in manual occupations

\section{Key messages}

What is already known about this subject?

- Non-manual occupational status has been found to be associated with more total or leisure time physical activity, but with less occupational physical activity. However, previous reports on differences in physical activity between occupational categories have mostly relied on self-reports, included only a very limited number of occupations, or not distinguished between working days and days off. In addition, hourly activity patterns in different occupations have not been previously presented.

\section{What are the new findings?}

- We used objective methods to assess 24-hour physical activity patterns in aging workers from a wide variety of occupations.

- Distinctly different activity patterns were found between genders and across occupations: women were more active than men during both working days and days off, and manual workers were more active during working days than non-manual workers.

- No differences during leisure time were observed between occupations.

How might this impact on policy or clinical practice in the foreseeable future?

- Occupational physical activity contributes markedly to total daily physical activity among aging workers. Since low physical activity is associated with increased risk of early exit from employment, more attention should be paid to possibilities of increasing physical activity during working days in non-manual workers and among men.

have more total and occupational physical activity, while there are no differences in physical activity levels between occupational statuses during leisure time. $^{4-8}$

With the population aging, extending working lives has become a priority in many high-income countries. ${ }^{910}$ Physical activity is one potential factor sustaining workability as low physical activity is one risk factor for early exit from employment 
via disability retirement. ${ }^{11}$ In addition, the incidence of chronic conditions (such as musculoskeletal and cardiovascular diseases) that are sensitive to physical activity increase sharply with age, as do the potential benefits of intervening. ${ }^{10}$ Therefore, identifying possible risk groups with low physical activity among aging workers is important.

Continuous monitoring of physical activity for 24-hours/day for multiple days has lately become possible with wrist-worn accelerometers which provide an alternative to traditional hip placement with increased compliance. ${ }^{3} 12$ Some recent studies have presented 24-hour activity patterns, which offer a detailed graphical view to activity levels throughout the day, showing when and how active people are during the day. ${ }^{13-18}$ These studies have compared activity patterns in older adults, mainly between genders ${ }^{19-23}$ and different age groups, ${ }^{15} 202324$ and between different days of the week. ${ }^{14}{ }^{17}$ However, we are not aware of studies comparing activity patterns between different occupational categories on working days and days off, information which would allow planning of targeted interventions aimed at increasing physical activity, for example, at the workplaces during working time.

Using wrist-worn accelerometer data from the Finnish Retirement and Aging Study (FIREA), our aim was to characterise the 24-hour patterns of physical activity by gender and occupational status among aging workers both on working days and days off. We also examined the association between occupational status and physical activity volume between working days and days off, and between working time and leisure time on working days.

\section{METHODS}

\section{Setting and participants}

FIREA is an ongoing longitudinal cohort study of older adults in Finland established in 2013. ${ }^{25}$ The FIREA study is conducted in line with the Declaration of Helsinki. The FIREA survey cohort included all public sector employees whose individual estimated retirement date was in 2014-2019, who were working in one of the 27 municipalities in South-West Finland or in the nine selected cities or five hospital districts around Finland during 2012, and who responded to at least one of the FIREA questionnaires $(n=6679)$. Information on individual estimated retirement date was obtained from the pension insurance institute for the municipal sector in Finland (Keva), and the working status at the time of activity measurement was self-reported. Participants were first contacted 18 months prior to their estimated retirement date by sending a questionnaire. Workers $>50$ years of age are defined as aging workers; ${ }^{9}$ thus the participants of this study, with a mean age of 62.4 years, were at the oldest end of the aging worker spectrum.

Of the Finnish-speaking FIREA survey participants, 2643 were eligible for this activity substudy based on their estimated retirement year and self-reported working status (online supplementary figure S1). The eligible participants were invited by mail to participate in the activity substudy. Of the 938 participants (36\% of the eligible) who returned the informed consent and were sent an accelerometer, 29 did not wear the accelerometer and 6 had technical problems during the measurement. A further 25 participants were excluded because they had $\leq 4$ valid days of $\geq 10$ hours of waking wear time per day where waking time was defined by an algorithm available in ActiLife software. ${ }^{26}$ This left 878 participants in the analyses $(33 \%$ of the eligible and $94 \%$ of those who were sent an accelerometer).

\section{Activity measurement}

Physical activity was measured over seven consecutive days and six consecutive nights with triaxial ActiGraph wActiSleep-BT accelerometers (ActiGraph, Pensacola, Florida, USA). The triaxial accelerometer measures activity as acceleration of the part of the body where the device is attached in three orthogonal planes, that is, axes. ${ }^{1215}$ Participants were instructed to wear the device on their non-dominant wrist at all times, including during water-based activities such as swimming, but to remove it for sauna. In an accompanying log, the participants were asked to record information about working day (working day or day off) and, for working days, time of the beginning and end of each work shift. Data collection took place between September 2014 and February 2018 during all the four seasons (26\% spring, 17\% summer, 30\% autumn, 27\% winter).

Data from the accelerometers were downloaded and converted into $60 \mathrm{~s}$ epochs in ActiLife software, V.6.13 (ActiGraph, Pensacola, Florida, USA). We used the vector magnitude (VM) counts per minute (CPM) which were calculated as the square root of the sum of squared activity counts of the three axes. Currently, no validated count cut-offs for different activity intensities for wrist-worn accelerometers are available in the ActiLife software. We included wear time between the first and last times recorded in the participant log and excluded non-wear time using the algorithm developed by Choi, which has been validated for wrist-worn triaxial accelerometers. ${ }^{27}$ Hours with less than $60 \mathrm{~min}$ of accelerometer counts were excluded $(<2 \%$ of the hours) from the activity pattern analyses.

\section{Assessment of occupational category}

Occupational title codes in 2012 were obtained from the pension insurance institute and categorised into manual and non-manual status by the International Standard Classification of Occupations (ISCO). Manual occupations were further categorised into 'managers and professionals' (ISCO classes 1-2, for example, physicians and teachers), and 'associate professionals' (ISCO classes 3-4, for example, registered nurses and secretaries). Non-manual occupations were categorised into 'service workers' (ISCO class 5, for example, practical nurses and cooks) and 'manual workers' (ISCO classes 6-9, for example, maintenance workers and cleaners). ${ }^{28}$

\section{Assessment of covariates}

We obtained participants' gender and date of birth from the pension insurance institute. Current, doctor-diagnosed cardiovascular diseases (angina pectoris, myocardial infarction or cerebrovascular disease), musculoskeletal diseases (osteoarthritis, osteoporosis, sciatica, fibromyalgia and rheumatoid arthritis) and diabetes, as well as mobility limitation (difficulty in climbing one flight of stairs or walking several blocks) ${ }^{29}$ were derived from the questionnaires. Body mass index (BMI) was calculated from self-reported weight and height $\left(\mathrm{kg} / \mathrm{m}^{2}\right)$. Participants' residential neighbourhood on $250 \times 250 \mathrm{~m}$ map grids was also categorised according to the Finnish Environment Institute's urban-rural classification as inner urban area (compact and densely built area with continuous development) or other. ${ }^{30}$

\section{Statistical analysis}

To examine selection into the activity substudy, we examined whether gender, age, occupational category, self-reported physical activity and self-reported sitting time differed between those who consented in the accelerometer substudy and those who were eligible for accelerometer measurements but did not 
consent. The differences in categorical variables were tested with the $\chi^{2}$ test and differences in continuous variables with the Student's t-test.

To visualise activity levels across the day, we plotted the mean CPM against hour of the day by gender and occupational categories separately for working days and days off. We calculated every participant's mean CPM for each 24-hours of each day, and then averaged the CPM for each hour across all valid days. All the included participants had data from all the 24-hours of the day. To describe 24-hour activity patterns between occupational statuses, we used linear models with generalised estimating equations (GEEs) with exchangeable correlation structure and estimated the mean CPM levels with 95\% CI per hour. The GEE model takes into account the intraindividual correlation between measurements.

To compare total daily physical activity volume, we used mean VM CPM during waking wear time, calculating them for all days ( $\mathrm{n}=878$, all participants, total number of days 6025), and separately for working days and days off $(n=771$, only participants who reported working days and had $\geq 1$ working day and $\geq 1$ day off, total number of working days 3374 , total number of days off 1916). When focusing on working days, we calculated the mean CPM separately for physical activity during working time (that is, occupational physical activity) and during leisure time based on the reported working times on the daily $\operatorname{logs}(n=731$, only participants who reported their working time and had $\geq 1$ working day and $\geq 1$ day off). Both days off and leisure time on working days were considered to represent leisure-time physical activity. Because we observed interaction effects between gender and occupational status on total activity counts ( $\mathrm{p}$ for interaction 0.01 ), we stratified the analyses by gender. First, we compared mean CPM between men and women and between the four occupational categories during all days using analysis of variance (ANOVA). Second, we compared mean activity counts between working days and days off, and third, between different times of the working days, in the gender and occupational categories, using repeated measures of ANOVA. We adjusted the models for gender, age, occupational category and duration of waking wear time. As a sensitivity analysis, we adjusted the models additionally for chronic diseases (yes/no), mobility limitation (yes/no), BMI (continuous) and living in inner urban area (yes/no). The statistical analyses were performed using SAS V.9.4 (SAS Institute, Cary, North Carolina, USA).

\section{RESULTS}

Mean wear time for the accelerometer was 22 hours $41 \mathrm{~min}$, 23 hours $33 \mathrm{~min}$ and 21 hours $5 \mathrm{~min}$ for all days, working days and days off, respectively. Manual and non-manual workers did not differ in terms of age, gender, chronic diseases, mobility limitation, BMI or living in urban neighbourhood (table 1). Online supplementary table S1 presents the comparison of sociodemographic characteristics and activity indicators between the eligible participants who did or did not consent to accelerometer measurement. Compared with the not consented participants, there were more women (consented: $\mathrm{n}=795,85 \%$, not consented: $\mathrm{n}=1337,78 \%)$ and 'managers and professionals' (consented: $\mathrm{n}=355,38 \%$, not consented: $\mathrm{n}=501,29 \%)$ among the consented participants. There were less inactive people by self-report among the consented $(n=134,14 \%)$ than among those who did not consent to the measurements $(\mathrm{n}=314,18 \%)$ but no differences were seen in age and self-reported total daily sitting time ( 8.1 hours/day vs 8.1 hours/day).

Unadjusted 24-hour activity patterns appeared to differ between working days and days off (figure 1, panel A). Daily activity was initiated earlier on working days than on days off. There were two activity peaks during the working days: one in the morning, approximately between 6:00 and 8:00, and one in the afternoon between 15:00 and 17:00, during times corresponding with commuting to and from the workplace. Physical activity during days off peaked before midday and decreased thereafter, with the decrease becoming more rapid towards the evening hours.

Despite similar patterns in men and women, women had higher hourly CPM during most of the daytime during working days and morning hours during days off. Overall, women (mean CPM 2580, 95\% CI 2540 to 2620) were more active than men (mean CPM 2110, 95\% CI 2020 to 2200, p <0.001). The mean daily activity counts were also higher for women than for men during both working days and days off (table 2), as well as during working time and leisure time during working days (table 3 ). The sex differences remained significant after further adjustments for chronic diseases, mobility limitation, BMI and living area (online supplementary tables S2 and S3).

Figure 1, panel B shows 24-hour activity patterns for working days and days off by occupational statuses among men and women. During working days, men and women in manual occupations were more active than men and women, respectively, in non-manual occupations especially during the usual working

Table 1 Comparison between participants in manual and non-manual occupations in the study sample

\begin{tabular}{|c|c|c|c|c|}
\hline & $\begin{array}{l}\text { Sample total } \\
\mathrm{n}=878\end{array}$ & $\begin{array}{l}\text { Non-manual occupation } \\
\mathrm{n}=601\end{array}$ & $\begin{array}{l}\text { Manual occupation } \\
\mathrm{n}=277\end{array}$ & $\mathrm{~N}$ missing \\
\hline Women, $\mathrm{n}(\%)$ & $742(85 \%)$ & $503(84 \%)$ & $239(86 \%)$ & 0 \\
\hline Occupational category, n (\%) & & & & 0 \\
\hline Managers and professionals (ISCO classes 1-2) & $342(39 \%)$ & $342(57 \%)$ & & \\
\hline Associate professionals (ISCO classes 3-4) & $259(29 \%)$ & $259(43 \%)$ & & \\
\hline Chronic disease, $\mathrm{n}(\%)$ & $456(52 \%)$ & $307(51 \%)$ & $149(54 \%)$ & 14 \\
\hline Mobility limitation, $n(\%)$ & $21(2 \%)$ & $17(3 \%)$ & $4(1 \%)$ & 18 \\
\hline Body mass index, $\mathrm{kg} / \mathrm{m}^{2}$, mean (SD) & $26.6(4.6)$ & $26.6(4.7)$ & $26.6(4.2)$ & 29 \\
\hline Living in inner urban area, $\mathrm{n}(\%)$ & $421(48 \%)$ & $300(50 \%)$ & $121(44 \%)$ & 5 \\
\hline
\end{tabular}

ISCO, International Standard Classification of Occupations. 


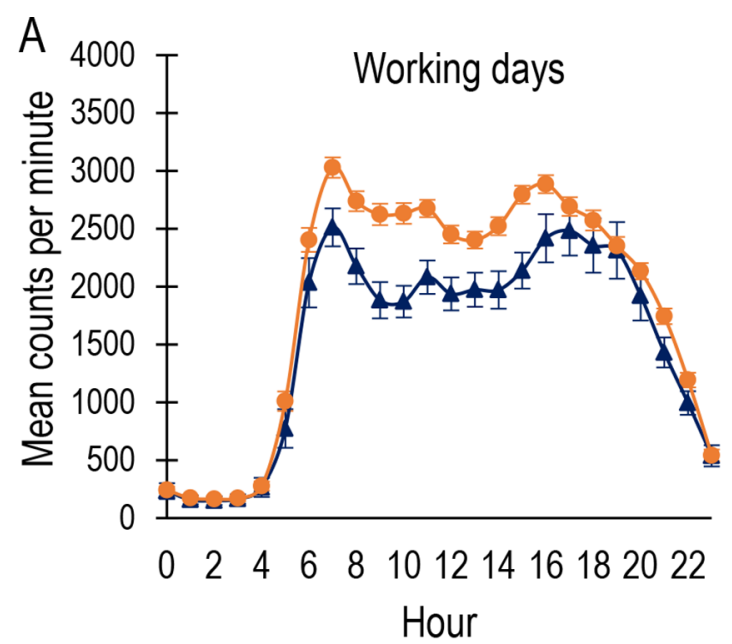

$\rightarrow$ Men $(n=115) \rightarrow-$ Women $(n=656)$

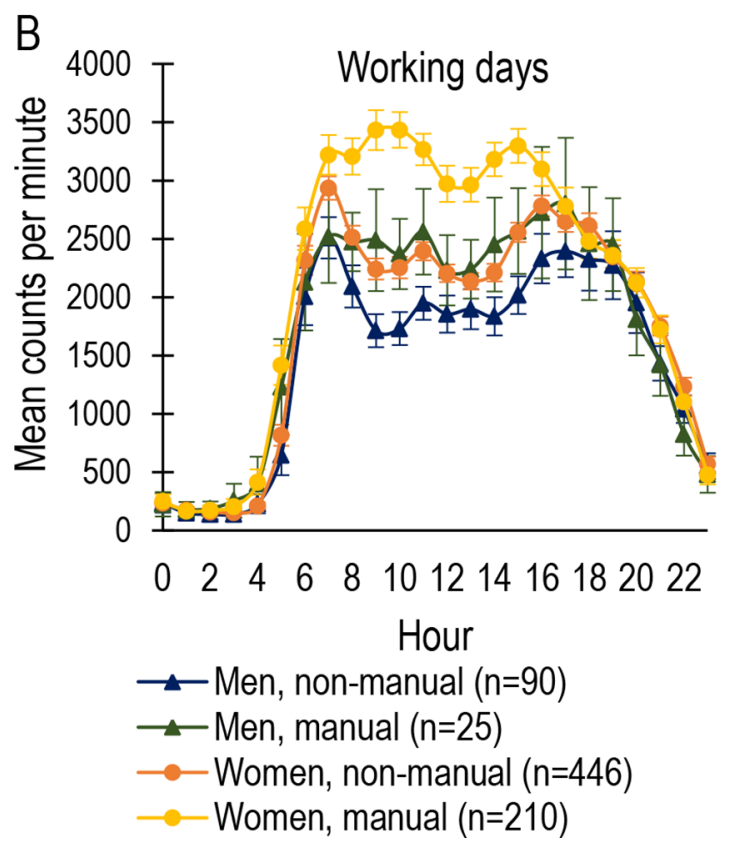

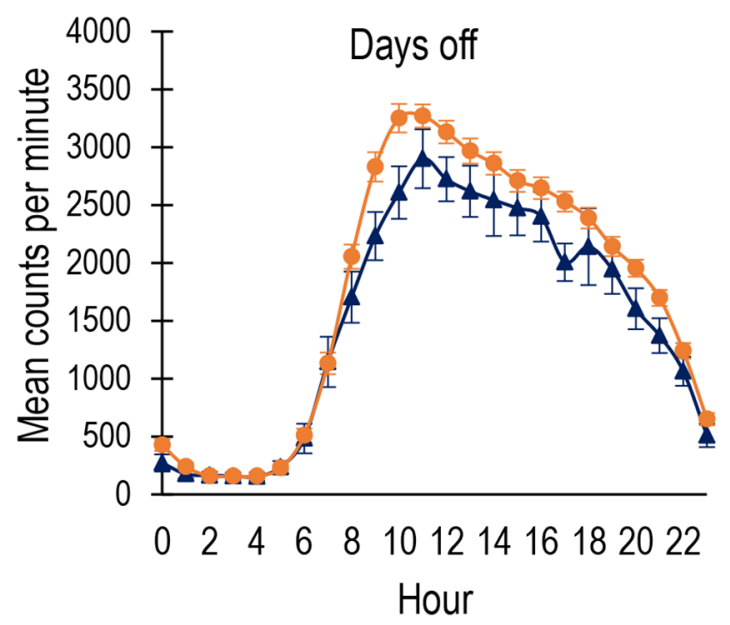

$\rightarrow$ Men $(\mathrm{n}=115) \rightarrow-$ Women $(\mathrm{n}=656)$

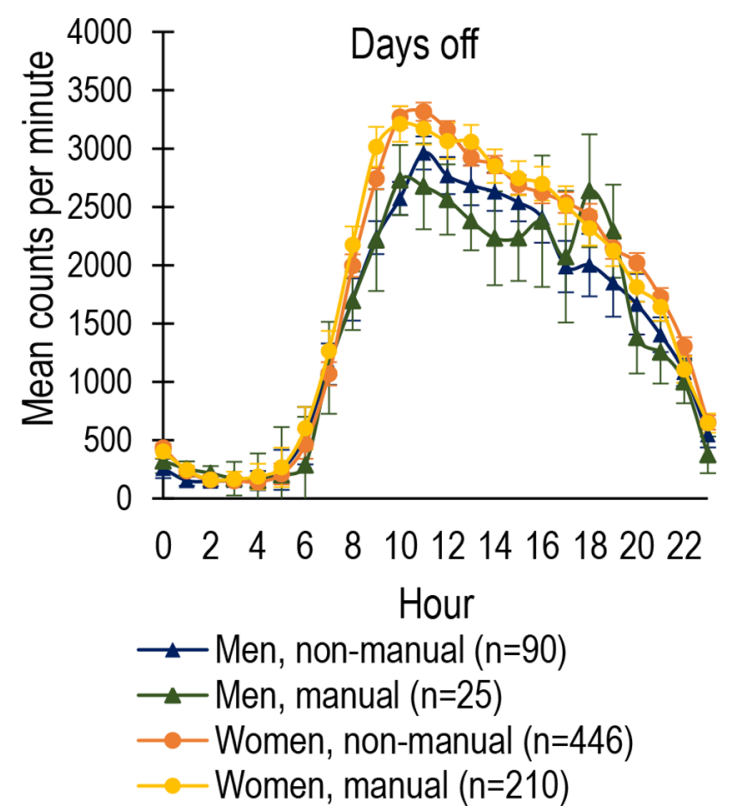

Figure 1 Twenty-four-hour activity patterns during working days and days off for (A) men and women and (B) men and women in different occupational statuses. Lines present mean hourly activity and error bars denote $95 \% \mathrm{Cl}$.

time from 6:00 to 16:00. Hourly CPM was at its highest level in women in manual occupations during working days.

When total daily activity volume was examined, women in 'managers and professionals' and 'associate professionals' occupational categories were more active than women in 'service workers' or 'manual workers' categories, and women in 'manual workers' category were more active than women in 'service workers' category both during working days (table 2 and supplementary table S2) and during working times (table 3 and online supplementary table S3). In general, the differences in total activity volume between occupational categories were less pronounced among men. Among men, 'manual workers' were more active than 'managers and professionals', during both working days and working times (tables 2 and 3). Additionally, 'manual workers' were more active than 'associate professionals' during working time among men (table 3). Further adjustments led to few changes in the results among men: during working days 'managers and professionals' were less active than 'associate professionals' (online supplementary table S2) and the working time difference between 'manual workers' and 'associate professionals' disappeared (online supplementary table S3). Among both men and women, no differences in total activity volume were seen between occupational categories during days off (table 2 and online supplementary table S2) or leisure time during working days (table 3 and online supplementary table S3).

Women in manual occupations were more active than women in non-manual occupations during working days than days off (table 2) and during working time than leisure time on working days (table 3 ). This pattern was less clear among men, where 'manual workers' were more active on working days than days off (table 2), but had similar level of activity during working time and leisure time on working days (table 3). On the contrary, women in non-manual occupations and men in 'managers and professionals' category had higher activity level during leisure time compared with working days (table 2) and working time 
Table 2 Mean waking time activity counts per minute in men and women and different occupational categories during all days, working days and days off

\begin{tabular}{|c|c|c|c|c|c|c|c|c|c|}
\hline \multirow[b]{2}{*}{ Variable } & \multirow{2}{*}{$\begin{array}{l}\text { n for all } \\
\text { days }\end{array}$} & \multicolumn{2}{|l|}{ All days } & \multirow{2}{*}{$\begin{array}{l}\mathrm{n} \text { for } \\
\text { working } \\
\text { days and } \\
\text { days off }\end{array}$} & \multicolumn{2}{|c|}{ Working days } & \multicolumn{2}{|l|}{ Days off } & \multirow{2}{*}{$\begin{array}{l}\text { P values } \\
\text { for day } \\
\text { difference }\end{array}$} \\
\hline & & Mean & $95 \% \mathrm{Cl}$ & & Mean & $95 \% \mathrm{Cl}$ & Mean & $95 \% \mathrm{Cl}$ & \\
\hline All* & 878 & 2510 & 2470 to 2540 & 771 & 2530 & 2480 to 2570 & 2530 & 2480 to 2580 & 0.86 \\
\hline \multicolumn{10}{|l|}{ Gendert } \\
\hline Men & 136 & 2110 & 2020 to 2200 & 115 & 2110 & 2000 to 2230 & 2260 & 2150 to 2380 & 0.004 \\
\hline Women & 742 & 2580 & 2540 to 2620 & 656 & 2580 & 2530 to 2630 & 2600 & 2550 to 2650 & 0.29 \\
\hline$P$ values for gender difference & & $<0.001$ & & & $<0.001$ & & $<0.001$ & & \\
\hline \multicolumn{10}{|l|}{ Men, by occupational category } \\
\hline Managers and professionals & 72 & 2060 & 1930 to 2180 & 69 & 2010 & 1900 to 2120 & 2270 & 2120 to 2420 & 0.01 \\
\hline Associate professionals & 26 & 2110 & 1900 to 2310 & 21 & 2160 & 1950 to 2360 & 2120 & 1850 to 2380 & 0.22 \\
\hline Service workers & 13 & 2260 & 1960 to 2550 & 10 & 2270 & 1980 to 2560 & 2260 & 1970 to 2540 & 0.51 \\
\hline Manual workers & 25 & 2150 & 1940 to 2360 & 15 & 2440 & 2220 to 2650 & 2100 & 1870 to 2330 & 0.0007 \\
\hline$P$ values for differences in occupations & & 0.68 & & & 0.07 & & 0.66 & & \\
\hline \multicolumn{10}{|l|}{ Women, by occupational category $\ddagger$} \\
\hline Managers and professionals & 270 & 2460 & 2390 to 2520 & 245 & 2390 & 2320 to 2560 & 2570 & 2490 to 2650 & $<0.001$ \\
\hline Associate professionals & 233 & 2500 & 2440 to 2570 & 201 & 2490 & 2410 to 3000 & 2600 & 2500 to 2700 & 0.001 \\
\hline Service workers & 197 & 2770 & 2700 to 2850 & 173 & 2910 & 2810 to 3390 & 2600 & 2490 to 2700 & $<0.001$ \\
\hline Manual workers & 42 & 2910 & 2750 to 3070 & 37 & 3200 & 3000 to 3390 & 2460 & 2250 to 2670 & $<0.001$ \\
\hline$P$ values for differences in occupations & & $<0.001$ & & & $<0.001$ & & 0.62 & & \\
\hline
\end{tabular}

*Adjusted for gender, age, occupational category and waking wear time.

†Analyses adjusted for age, occupational category and waking wear time.

‡Analyses adjusted for age, gender and waking wear time.

(table 3). In addition, after further adjustments, men in 'associate professionals' category were also more active during leisure time on working days than during working times (online supplementary table S3).

\section{DISCUSSION}

In this study we investigated the 24-hour patterns of objectively measured physical activity in a large sample of aging public sector workers in Finland. Women were more active than men throughout the days. Activity patterns were distinctly different between different occupational categories and between working days and days off. Women working in manual occupations were more active than women in non-manual occupations during all days, working days and working times, while men working in manual occupations were more active than men in non-manual occupations only during working time. No differences in total activity volume between different occupational groups were found during days off and leisure time on working days.

Table 3 Mean waking time activity counts per minute in men and women and in different occupational categories during working time and leisure time on working days

\begin{tabular}{|c|c|c|c|c|c|c|}
\hline \multirow[b]{2}{*}{ Variable } & \multirow[b]{2}{*}{$\mathrm{n}$} & \multicolumn{2}{|c|}{ Working time } & \multicolumn{2}{|c|}{ Leisure time on working days } & \multirow{2}{*}{$\begin{array}{l}\text { P values for day } \\
\text { difference }\end{array}$} \\
\hline & & Mean & $95 \% \mathrm{Cl}$ & Mean & $95 \% \mathrm{Cl}$ & \\
\hline All $^{*}$ & 731 & 2510 & 2440 to 2570 & 2540 & 2490 to 2590 & 0.31 \\
\hline \multicolumn{7}{|l|}{ Gendert } \\
\hline Men & 109 & 2000 & 1890 to 2110 & 2350 & 2220 to 2480 & 0.0001 \\
\hline Women & 622 & 2590 & 2530 to 2660 & 2580 & 2530 to 2630 & 0.7 \\
\hline$P$ values for gender difference & & $<0.001$ & & $<0.001$ & & \\
\hline \multicolumn{7}{|l|}{ Men by occupational category $\ddagger$} \\
\hline Managers and professionals & 64 & 1800 & 1660 to 1930 & 2240 & 2070 to 2410 & $<0.001$ \\
\hline Associate professionals & 21 & 1930 & 1680 to 2180 & 2270 & 1970 to 2570 & 0.052 \\
\hline Service workers & 10 & 2240 & 1840 to 2630 & 2480 & 2080 to 2880 & 0.49 \\
\hline Manual workers & 14 & 2440 & 2150 to 2720 & 2450 & 2170 to 2720 & 0.85 \\
\hline$P$ values for differences in occ & & 0.001 & & 0.88 & & \\
\hline \multicolumn{7}{|l|}{ Women by occupational category } \\
\hline Managers and professionals & 227 & 2220 & 2120 to 2390 & 2560 & 2480 to 2640 & $<0.001$ \\
\hline Associate professionals & 191 & 2290 & 2190 to 3330 & 2620 & 2540 to 2700 & $<0.001$ \\
\hline Service workers & 169 & 3200 & 3080 to 4320 & 2590 & 2500 to 2680 & $<0.001$ \\
\hline Manual workers & 35 & 3940 & 3560 to 4320 & 2580 & 2390 to 2770 & $<0.001$ \\
\hline$P$ values for differences in occ & & $<0.001$ & & 0.75 & & \\
\hline
\end{tabular}

*Adjusted for gender, age, occupational category and waking wear time.

†Analyses adjusted for age, occupational category and waking wear time.

¥Analyses adjusted for age, gender and waking wear time. 
The observed 24-hour activity follows the patterns reported previously, with large differences in the patterns between weekdays and weekends. ${ }^{13} 141617$ Similar to our results, previous studies with younger populations from Finland, ${ }^{14}$ the $\mathrm{UK}^{16}$ and Singapore ${ }^{17}$ have also observed activity peaks during times most likely corresponding to commuting to and from work during working days. These activity peaks indicate that commuting contributes to total physical activity. In an international comparison of industrialised countries, Finland was in the mid-level with $31 \%$ of trips taken by walking or bicycling, while the range was from $6 \%$ to $50 \% .^{31}$ Furthermore, commuting by public transport can also include incidental physical activity, for example, walking from the bus stop to the workplace. ${ }^{32}$ However, the results regarding commuting peaks should be interpreted with caution, because the simultaneous nature of commuting can exaggerate the peaks even though activity level itself would not be very high. More research on active and passive commuting is warranted to define the extent to which active commuting contributes to total physical activity.

In our study, aging women accrued more total, occupational and leisure-time physical activity than aging men, which is in line with the latest population-based, self-reported information from Finland. ${ }^{33}$ In general, men have been reported to be more active than women, especially when using self-reported physical activity. ${ }^{34}$ However, several studies using objective physical activity measurements have found no differences in activity levels between men and women, ${ }^{15}{ }^{20}$ while other studies, similarly to our study, found higher activity among women than men, especially in the older age groups. ${ }^{23} 35$ There are several potential explanations for the gender differences. First, gender-based segregation of occupations is particularly strong in Finland, especially in the public sector. ${ }^{36}$ Most of the women work in healthcare, education and social services. Many men also work in healthcare and education, but a high proportion of men also work in administration and technical fields. ${ }^{37}$ The occupations with more women require more physical activity, which probably created most of the gender differences in occupational physical activity that we observed in our study. The requirements of work are usually the same for all the employees, thus we do not expect younger and older workers to have different activity patterns during working time. Second, active commuting is more common among women than among men. In a population-based study among adult Finns, $22 \%$ of women, but only $14 \%$ of men, reported active commuting in the age group of 60-64 years. ${ }^{33}$ Third, higher level of leisure-time physical activity among women might be explained by household chores, which are more commonly taken up by women especially in this age group, ${ }^{38}$ and which also are activities that might be well captured with the wrist-worn accelerometers. ${ }^{15} 22$

Not surprisingly, we found higher total and occupational physical activity among aging workers with manual than non-manual occupations. The absolute differences in working time physical activity were larger in women than in men across different occupations. Our results thus highlight that, among aging workers, work is a defining factor for physical activity during working days, and that the differences in occupational physical activity are large. Therefore, different types of interventions are needed for people in different occupations. In our study, men in non-manual occupations were especially at risk of getting too little physical activity during working days and working times. They would, for example, most probably benefit from workplace interventions such as using activity-permissive workstations, increasing physical activity, such as walking up the stairs, during working time, or increasing active commuting. ${ }^{39}$
We found no differences in leisure-time physical activity between the occupational categories, which is contrary to some previous studies which have used self-reported physical activity as an outcome. ${ }^{2}$ Nevertheless, our results are similar to several studies using objective measures for physical activity which have not observed differences in leisure-time physical activity between manual and non-manual occupations. ${ }^{5-8}$ Furthermore, participants in non-manual occupations were less active on working days than on days off, while those in manual occupations were more active on working days than days off. Unfortunately, we were not able to derive more concrete measures of physical activity, such as minutes in MVPA, to define whether workers in our study were more active or less active during days off than in other populations. However, it is possible that aging workers in manual occupations feel fatigued and respond to the fatigue by being less active on days off than during working days. ${ }^{18}$

The strengths of this study include objective 24-hour measurement of physical activity, assessment of occupational status by registry information, information of working days and working times, and inclusion of a large sample of participants representing a wide variation of occupations. However, accelerometers have well known weaknesses, such as not being able to detect specific types of non-impact activities, like cycling. ${ }^{3}$ In addition, as all the accelerometers only detect movement of the part of the body where they are attached to; wrist-worn accelerometers may therefore overestimate some movements, such as household activities including vigorous hand movements. ${ }^{3}$ We were not able to provide time spent in different activity intensities, such MVPA from the wrist-worn accelerometer. However, CPM have been previously used to describe patterns of physical activity ${ }^{24} 40$ and the CPM patterns follow closely the MVPA patterns of waistworn devices. ${ }^{24}$ Furthermore, the activity patterns from wristworn and hip-worn accelerometers follow the same shape, even though the wrist-worn devices give around five times higher counts due to the larger movement of the wrist compared with the hip. ${ }^{22}$ In addition, due to the lack of consensus in identifying spurious counts, we did not exclude spurious counts from the analyses. Although there were only $15 \%$ of men in the sample, this is representative of the public sector in Finland as 78\% of people working in the local government are women. ${ }^{36}$ The narrow age range of the participants reflects aging workers and might restrict generalisation to younger workers. Furthermore, compared with the not consented participants, the consented participants had non-manual occupations slightly more often and higher self-reported activity levels, which should be taken into account when interpreting the results.

In conclusion, we found that the amount and timing of physical activity varies between gender and occupational categories among aging workers. Women were more active than men and those in manual occupations had more total and occupational physical activity than those in non-manual occupations. We did not find differences in the level of leisure-time physical activity between the occupational categories. Since low physical activity is associated with increased risk of early exit from employment, more attention should be paid to promoting physical activity of older workers at workplaces, especially among men and people in non-manual occupations. However, daily activity profiles highlighted that during working days, physical activity is highest during times corresponding to commuting.

Contributors SS and JV conceived and designed this study and designed the data collection. AP analysed the data and drafted the first manuscript, with critical revisions from SS, TL, AK, JP and JV. All authors approved the final version of the manuscript. 
Funding This study was supported by the Academy of Finland (projects 286294 and 294154 for SS 309526 for TL) and Ministry of Education and Culture of Finland.

Competing interests None declared.

Patient consent Obtained.

Ethics approval Ethics Committee of Hospital District of South-West Finland.

Provenance and peer review Not commissioned; externally peer reviewed.

\section{REFERENCES}

1 Choi J, Lee M, Lee JK, et al. Correlates associated with participation in physical activity among adults: a systematic review of reviews and update. BMC Public Health 2017:17:356

2 O'Donoghue G, Kennedy A, Puggina A, et al. Socio-economic determinants of physical activity across the life course: A "DEterminants of Dlet and Physical ACtivity" (DEDIPAC) umbrella literature review. PLoS One 2018;13:e0190737.

3 Schrack JA, Cooper R, Koster A, et al. Assessing daily physical activity in older adults: unraveling the complexity of monitors, measures, and methods. J Gerontol A Biol Sci Med Sci 2016;71:1039-48.

4 Steele R, Mummery K. Occupational physical activity across occupational categories. J Sci Med Sport 2003;6:398-407.

5 Schofield G, Badlands H, Oliver M. Objectively-measured physical activity in New Zealand workers. I Sci Med Sport 2005;8:143-51.

6 Ruiz-Tendero G, Salinero-Martin JJ, Webster AL, et al. Measurement of physical activity levels of workers on a Spanish university campus using accelerometry technology. Journal of Human Movement Studies 2006;51:321-35.

7 Ramey SL, Perkhounkova Y, Moon M, et al. Physical activity in police beyond selfreport. J Occup Environ Med 2014;56:338-43.

8 Pulakka A, Stenholm S, Bosma H, et al. Association between employment status and objectively measured physical activity and sedentary behavior-the maastricht study. J Occup Environ Med 2018;60:309-15.

9 IImarinen JE. Aging workers. Occup Environ Med 2001;58:546-51.

10 Bloom DE, Chatterji S, Kowal P, et al. Macroeconomic implications of population ageing and selected policy responses. Lancet 2015;385:649-57.

11 Robroek SJ, Reeuwijk KG, Hillier FC, et al. The contribution of overweight, obesity, and lack of physical activity to exit from paid employment: a meta-analysis. Scand J Work Environ Health 2013;39:233-40.

12 Troiano RP, McClain JJ, Brychta RJ, et al. Evolution of accelerometer methods for physical activity research. Br I Sports Med 2014;48:1019-23.

13 Clemes SA, O'Connell SE, Edwardson CL. Office workers' objectively measured sedentary behavior and physical activity during and outside working hours. J Occup Environ Med 2014;56:298-303.

14 Mutikainen S, Helander E, Pietilä J, et al. Objectively measured physical activity in Finnish employees: a cross-sectional study. BMJ Open 2014;4:e005927.

15 Schrack JA, Zipunnikov V, Goldsmith J, et al. Assessing the "physical cliff" : detailed quantification of age-related differences in daily patterns of physical activity. J Gerontol A Biol Sci Med Sci 2014;69:973-9.

16 Smith L, Hamer M, Ucci M, et al. Weekday and weekend patterns of objectively measured sitting, standing, and stepping in a sample of office-based workers: the active buildings study. BMC Public Health 2015;15:9.

17 Müller-Riemenschneider F, Ng SH, Koh D, et al. Objectively measured patterns of activities of different intensity categories and steps taken among working adults in a multi-ethnic Asian population. J Occup Environ Med 2016;58:e206-e211.

18 Wanigatunga AA, Simonsick EM, Zipunnikov V, et al. Perceived fatigability and objective physical activity in mid- to late-life. J Gerontol A Biol Sci Med SCi 2018;73:630-5.
19 Arnardottir NY, Koster A, Van Domelen DR, et al. Objective measurements of daily physical activity patterns and sedentary behaviour in older adults: age, gene/ environment susceptibility-Reykjavik Study. Age Ageing 2013;42:222-9.

20 Martin KR, Koster A, Murphy RA, et al. Changes in daily activity patterns with age in U.S. men and women: National Health and Nutrition Examination Survey 2003-04 and 2005-06. J Am Geriatr Soc 2014;62:1263-71.

21 Xiao L, Huang L, Schrack JA, et al. Quantifying the lifetime circadian rhythm of physical activity: a covariate-dependent functional approach. Biostatistics 2015;16:352-67.

22 Shiroma EJ, Schepps MA, Harezlak J, et al. Daily physical activity patterns from hipand wrist-worn accelerometers. Physiol Meas 2016;37:1852-61.

23 Huisingh-Scheetz M, Wroblewski K, Kocherginsky M, et al. The relationship between physical activity and frailty among U.S. older adults based on hourly accelerometry data. J Gerontol A Biol Sci Med Sci 2018;73:622-9.

24 Sartini C, Wannamethee SG, lliffe S, et al. Diurnal patterns of objectively measured physical activity and sedentary behaviour in older men. BMC Public Health 2015;15:609.

25 Leskinen T, Pulakka A, Heinonen OJ, et al. Changes in non-occupational sedentary behaviours across the retirement transition: the Finnish Retirement and Aging (FIREA) study. J Epidemiol Community Health 2018;72:695-701.

26 Pulakka A, Shiroma EJ, Harris TB, et al. Classification and processing of 24-hour wrist accelerometer data. J Meas Phys Behav 2018;1:51-9.

27 Choi L, Ward SC, Schnelle JF, et al. Assessment of wear/nonwear time classification algorithms for triaxial accelerometer. Med Sci Sports Exerc 2012;44:2009-16.

28 Statistics Finland. Classification of occupations. 2001 http://www.stat.fi/meta/ luokitukset/ammatti/001-2001/index_en.html (Accessed 9 May, 2018).

29 Guralnik JM, Ferrucci L, Simonsick EM, et al. Lower-extremity function in persons over the age of 70 years as a predictor of subsequent disability. N Engl I Med 1995;332:556-62.

30 Finnish Environment Institute SYKE. Urban-rural classification. 2018 http://www. ymparisto.fi/en-US/Living_environment_and_planning/Community_structure/ Information_about_the_community_structure/Urbanrural_classification (Accessed 7 Jun, 2018).

31 Bassett DR, Pucher J, Buehler R, et al. Walking, cycling, and obesity rates in Europe, North America, and Australia. J Phys Act Health 2008:5:795-814.

32 Flint E, Cummins S. Active commuting and obesity in mid-life: cross-sectional, observational evidence from UK Biobank. Lancet Diabetes Endocrinol 2016;4:420-35.

33 Koponen P, Borodulin K, Lundqvist A, et al. Terveys, toimintakyky ja hyvinvointi Suomessa - FinTerveys 2017 -tutkimus [Health, functional capacity and welfare in Finland - FinHealth 2017 study]. Helsinki, Finland: National Institute for Health and Welfare (THL), 2018.

34 Sallis JF, Bull F, Guthold R, et al. Progress in physical activity over the Olympic quadrennium. Lancet 2016;388:1325-36.

35 Doherty A, Jackson D, Hammerla N, et al. Large scale population assessment of physical activity using wrist worn accelerometers: the UK biobank study. PLoS One 2017:12:e0169649

36 Statistics Finland. Women and men in Finland 2016. Helsinki, Finland: Edita Publishing Oy, 2016

37 Statistics Finland. Suomen virallinen tilasto: Kuntasektorin palkat 2015 [Official Statistics of Finland: Local government sector wages and salaries 2015. 2015. http:// www.stat.fi/til/ksp/2015/ksp_2015_2016-05-10_fi.pdf (Accessed 14 Aug 2018).

38 Fahlén S. Equality at home - A question of career? Housework, norms, and policies in a European comparative perspective. Demogr Res 2016;S20:1411-40.

39 Keadle SK, Conroy DE, Buman MP, et al. Targeting reductions in sitting time to increase physical activity and improve health. Med Sci Sports Exerc 2017;49:1572-82.

40 Van Domelen DR, Koster A, Caserotti $\mathrm{P}$, et al. Employment and physical activity in the U.S. Am J Prev Med 2011;41:136-45. 